\title{
LKB1/PEA3/ $\triangle$ Np63 pathway regulates PTGS-2 (COX-2) transcription in lung cancer cells upon cigarette smoke exposure
}

\author{
Edward A. Ratovitski \\ Department of Dermatology; Johns Hopkins University School of Medicine; Baltimore, MD USA
}

Key words: inflammation, oxidative stress, cancer, oncogenes, tumor suppressors, transcription, lung, smoking, cyclooxygenase, p63, cell migration, cell invasiveness

\begin{abstract}
This is the first study to show that cigarette smoking induced the LKB1/PEA3/ANp63-dependent transcriptional regulation of inflammatory molecules, such as COX-2/PTGS-2. Using mainstream smoke extract (MSE) and sidestream smoke extract (SSE) as modeling tools for primary and secondhand smoking, we found that both MSE and SSE downregulated protein levels for LKB1, while upregulated protein levels for PEA3 and COX-2 in a dose-dependent manner. Using the endogenous ChIP analysis, we further found that the C/EBP $\beta, N F \kappa B, N F-Y(C H O P), P E A 3$ (ETS) and $\Delta$ Np63 proteins bound to the specific area (-550 to -130) of the COX-2 promoter, while forming multiple protein complexes in lung cancer cells exposed to MSE and SSE. Our results define a novel link between various transcription factors occupying the COX-2 promoter and cellular response to cigarette smoke exposure bringing a new component, $\Delta N p 63 \alpha$, showing a critical role for cooperation between various chromatin components in regulation of COX-2 expression and, therefore strengthening the central role of inflammatory process in tumorigenesis of epithelial cells, especially after cigarette smoke exposure (both primary and secondhand).
\end{abstract}

\section{Introduction}

Tobacco smoke contains over 4,700 chemical components that have been implicated in the etiology of oxidative stress-related diseases e.g., chronic obstructive pulmonary disease, Parkinson's disease, Alzheimer disease, asthma, cancer and cardiovascular disease. ${ }^{1-7}$ Epidemiological studies support the notion that lung cancers are directly caused by cigarette primary and secondhand smoking. ${ }^{1-3}$ Carcinogen exposure and chronic inflammation are two important events in tumor development, and both have been implicated in the development of many human epithelial cancers. ${ }^{4-6}$ Exposure to external factors including cigarette smoking, infectious agents, dietary carcinogens and hormonal imbalances could injure the tissue (e.g., lung) and lead to chronic inflammation., ${ }^{5,6}$ At the cellular and molecular levels, cigarette smoking might induce oxidative stress and DNA damage, implicated in the etiology of cancer and resulting in modulation of reactive oxygen species (ROS) production and the cell's own antioxidant defenses, therefore leading to activation of numerous signaling pathways underlying apoptosis and autophagy. ${ }^{8-10}$

Epithelial/mesenchymal transition (EMT) and increased cell motility/migratory/invasive phenotype were also found to occur during the development and progression of lung epithelial cancers. ${ }^{11-13}$ Thus, the understanding of mechanisms underlying these processes (apoptosis, angiogenesis, cell migration, invasiveness) in lung cancer would assist development of new therapeutic strategies. ${ }^{5,6,13}$

Studies of genetic mechanisms underlying lung cancer, along with other human cancers, demonstrated that tobacco exposure is causing inactivation of tumor suppressor genes via genetic/ epigenetic changes affecting many cellular processes. ${ }^{1,13,14}$ LKB1 tumor suppressor gene (also known as serine/threonine kinase-11, STK11) is capable to regulate other protein's function by phosphorylation, thereby affecting cell proliferation and survival..$^{15-21}$ Smoking has been linked to human epithelial cancers, which overexpress proteins implicated in inflammatory signaling pathways [e.g., NFKB, cyclin D1, cyclooxygenase (COX)-2 (also known as PTGS-2, prostaglandin-endoperoxide synthase-2)]. 7.22-32

We previously showed that that LKB1 physically and functionally associates with PEA3 leading to the PEA3 phosphorylation and subsequent PEA3 protein degradation via proteasomedependent pathway. ${ }^{16}$ We also showed that the downregulated PEA3 expression and activity leads to a subsequent downregulation of COX-2/PTGS-2 expression. ${ }^{16}$ We further showed that cells expressing mutant LKB1 deficient of kinase activity failed to downregulate PEA3 and activate COX-2 transcription, while increased cell invasiveness compared to cells with wild-type LKB1. ${ }^{16}$ Similarly, LKB1 knockdown by siRNA dramatically increased migration/invasiveness shown by lung cancer cells in vitro. However, lung cancer cells transfected with PEA3 


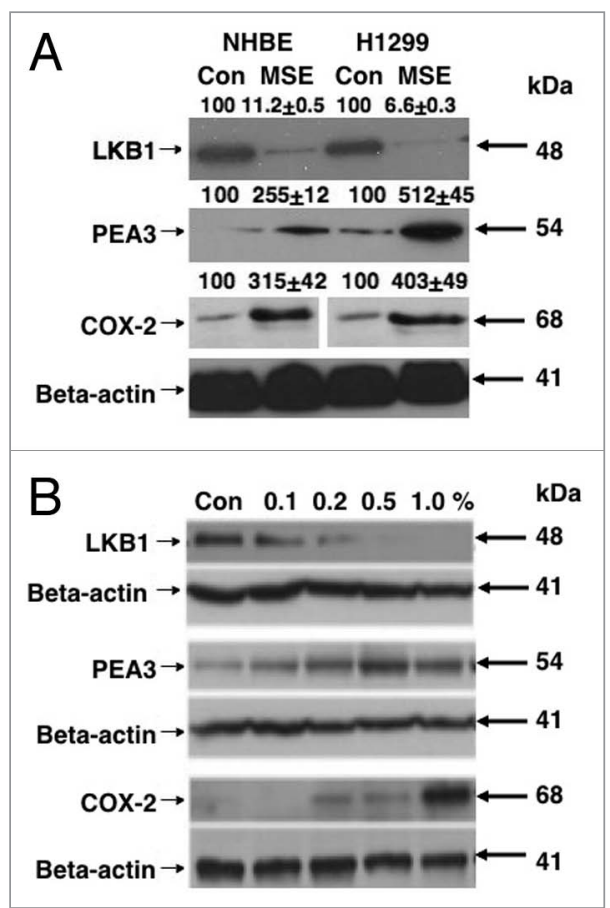

Figure 1. MSE affects the levels for LKB1, PEA3 and PTGS-2/COX-2 in normal lung and lung cancer cells. (A) NHBE normal lung and H1299 lung cancer cells were exposed to $0.5 \%$ MSE for $48 \mathrm{~h}$. (B) H1299 lung cancer cells were incubated with MSE in a dose-dependent manner (Con, control, $0.2,0.5,1.0$ and $2 \%$ MSE) for $24 \mathrm{~h}$. Total lysates were analyzed by immunoblotting with antibodies against LKB1, PEA3, PTGS-2/COX-2 and $\beta$-actin. Immunoblots were scanned and quantified by Image Quant software version 3.3 and normalized for the $\beta$-actin protein levels. Median data expressed as percentages of data obtained from control sample representing three independent experiments were shown above blot images. Statistical analysis was performed using a student t-test. ${ }^{16}$

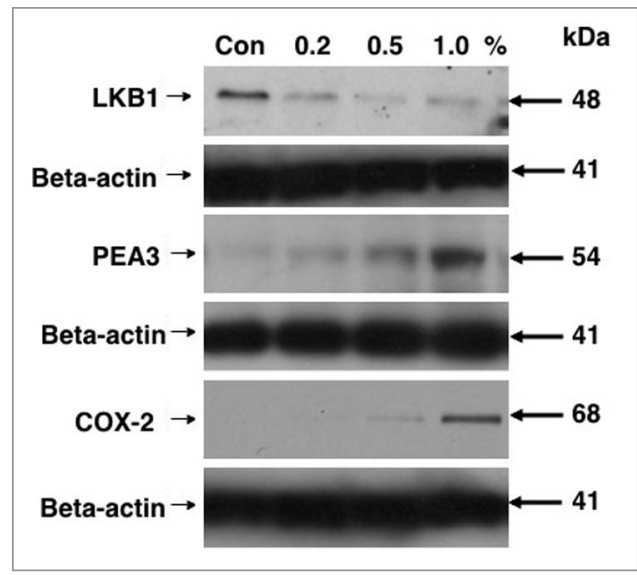

Figure 2. SSE affects the levels for LKB1, PEA3 and COX-2/PTGS-2 in lung cancer cells. $\mathrm{H} 1299$ cells were incubated with SSE in a dose-dependent manner (Con, control, $0.2,0.5$ and $1.0 \%$ SSE) for $48 \mathrm{~h}$. Total lysates were analyzed by immunoblotting with antibodies against LKB1, PEA3, COX-2/ PTGS-2 and $\beta$-actin. Immunoblots were scanned and quantified by Image Quant software version 3.3 and normalized for the $\beta$-actin protein levels. Median data expressed as percentages of data obtained from control sample representing three independent experiments were shown above blot images. Statistical analysis was performed using a student t-test. ${ }^{16}$
siRNA displayed decreased invasiveness, while the PEA3 forced expression resulted in decrease of epithelial markers and increase of mesenchymal markers suggesting that PEA3 stabilization due to LKB1 inactivation leads to a greater cancer cell invasiveness. ${ }^{16}$

In the current study, we provide the first evidence that cigarette smoke treatment [mainstream smoke extract (MSE) and sidestream smoke extract (SSE)] of cultured lung normal and cancer cells decreased LKB1 expression and elevated expression of both PEA3 (polyomavirus enhancer activator 2, also known as E1A enhancer binding protein 4) factor and COX-2/ PTGS-2 inflammatory signaling molecule. We showed that cigarette smoking affects the molecular processes underlying EMT of lung cancer/epithelial cells and involving LKB1 inactivation and PEA3/ANp63-mediated regulation of COX-2/PTGS-2. We defined a novel LKB1/PEA3/ $/ \mathrm{Np} 63 \alpha$ molecular pathway leading to COX-2/PTGS-2 regulation in human lung cancer cells exposed to mainstream and sidestream smokes therefore linking $\Delta \mathrm{Np} 63 \alpha$ to tumorigenesis and inflammation processes as a new biomarker for oxidative stress and DNA damage. ${ }^{33}$

\section{Results}

LKB1 is downregulated in lung tumor samples from patients affected by smoking. Recent report shows that normal human lung epithelial tissues overexpress LKB1, while in primary lung tumors (squamous cell carcinomas), LKB1 levels were dramatically downregulated. ${ }^{15,16}$ We previously showed that LKB1 overexpression led to a binding to and subsequent phosphorylation of the PEA3 transcription factor followed by downregulation of PEA3 and in turn inhibition of COX-2/PTGS-2 expression. ${ }^{16}$

In this study, we examined whether cigarette smoking exposure of lung normal and cancer cells affect the expression levels of LKB1, PEA3 and COX-2. We exposed normal human bronchiolar epithelial (NHBE) cells and H1299 lung cancer cells to 0.5\% MSE for $48 \mathrm{~h}$, and found that LKB1 protein levels were downregulated, while levels for PEA3 and COX-2/PTGS-2 were upregulated in both cell lines upon MSE exposure (Fig. 1A). We found that $\mathrm{H} 1299$ cells exposed to MSE in dose-dependent manner displayed altered expression of LKB1, PEA3 and COX-2/PTGS-2 (Fig. 1B). We further examined the effect of SSE on the protein levels of LKB1, PEA3 and COX-2/PTGS-2 in H1299 cells. We then found that $1 \%$ SSE added to cells for $48 \mathrm{~h}$ decreased the LKB1 protein levels, while upregulated the PEA3 and COX-2 protein levels (Fig. 2). We thus observed that both MSE and SSE decreased LKB1 protein levels in lung cancer cells.

PEA3 physically associates with the COX-2 specific transcription factors in lung cancer cells upon cigarette smoke exposure. We further examined molecular mechanisms underlying LKB1 downregulation and its effects on PEA3 transcriptional regulation of COX-2/PTGS-2 in CSE-exposed lung cancer cells and lung normal epithelial cells. We thus tested whether various putative transcription factors involved in regulation of COX-2 expression in lung cancer cells upon cigarette smoke exposure. First, we defined the consensus sequences for the potential transcription factors in the COX-2 promoter sequence (Sup. Material) using the TFSEARCH web-engine (http://mbs.cbrc.jp/rese-arch/db/TFSEARCH.html). 
The following cis-regulatory elements were found in the $1,700 \mathrm{bp} C O X-2$ promoter sequence: C/EBP $\beta$, NFкB, NF-Y, PEA3 and p63 (Fig. 3).

We then accessed whether these transcription factors endogenously bind to the COX-2 promoter in lung cancer cells after cigarette smoke exposure. We found that both MSE and SSE induced binding of the C/EBP $\beta$, NFкB, NF-YA, PEA3, p53 and $\mathrm{p} 63$ proteins to $\mathrm{COX}-2$ promoter evidenced by ChIP assay followed by RT-PCR assay given rise to a 420 bp product (Fig. 4). Since lung cancer cells were previously shown to predominantly express $\Delta \mathrm{Np} 63 \alpha$ isoform of p63 (reviewed in ref. 34), the antibody that exclusively recognizes the $\Delta \mathrm{Np} 63$ was used in these experiments. ${ }^{34,35}$

Previous reports pointed out the possibility for LKB1 to form protein-protein complexes with p53 (reviewed in ref. 36). We therefore tested whether p53 homolog $\Delta \mathrm{Np} 63 \alpha$ is forming protein complexes with LKB1 and the other transcription factors occupying the COX-2 promoter in lung cancer cells after cigarette smoke exposure. We found that, indeed, $\Delta \mathrm{Np} 63 \alpha$ formed protein-protein complexes with LKB1 in untreated cells (Fig. 5A), while the amount of these $\Delta \mathrm{Np} 63 / \mathrm{LKB} 1$ protein complexes dramatically decreased upon cigarette smoke exposure (Fig. 5A). In addition, the $\Delta \mathrm{Np} 63 \alpha$ protein associated with $\mathrm{C} / \mathrm{EBP} \beta$, NFкB, NF-YA and PEA3 in cells exposed to both MSE and SSE (Fig. 5A).

We previously showed that the PEA3 ETS domain interacted with the LKB1 kinase domain pLexA-LKB1-KD (1-300) in vitro. ${ }^{16}$ We also showed that the LKB1/ PEA3 protein complexes formed in transfected cells and endogenously in H1299 lung cancer cells found exclusively at the nucleus. ${ }^{16}$ To further understand the effect of molecular interactions between LKB1 and PEA3 in lung cancer cells exposed to cigarette smoke extract, we performed immunoprecipitation analysis of the LKB1/ PEA3 protein-protein complexes. We thus found that, while LKB1 is downregulated in lung cancer cells upon cigarette smoke exposure by both MSE and SSE (Figs. 1 and 2), the formation of protein complexes between LKB1 and PEA3 is dramatically diminished during cellular response to cigarette smoke (Fig. 5B).

Cigarette smoking exposure induces invasiveness, foci formation and survival of lung cancer cells. Our previous results supported the notion that the PEA3 overexpression can mediate
-1700 TCCACGCTCT TAGTTGAAAT TTCATGTAAG ATTCCATGCA ATAAATAGGA

-1650 GTGCCATAAA TGGAATGATG AAATATGACT AGAGGAGGAG AAAGGCTTCC C/EBPbeta

-1600 TAGATGAGAT GGAATTTTAG TCATCCGTGT CTCATGAAGA ATCAGATGTG -1550 TACACTAAGC AAAACAGTTA AAAAAAAAAC CTCCAAGTGA GTCTCTTATT

-1500 TATTTTTTTC TTATAAGACT TCTACAAATT GAGGTACCTG GTGTAGTTTT

-1450 ATTTCAGGTT TTATGCATGT ATTTTCCTGT AATGCTAAGG ACTTAGGACA P53RE STAT

-1400 TAACTGAATT TTCTATTTTC CACTTCTTTT CTGGTGTGTG TGTATATATA -1350 TATGTATATA TACACACACA CATATACATA TATATATTTT TTAGTATCTC -1300 ACCCTCACAT GCTCCTCCCT GAGCACTACC CAGGATAGAT GTTAAACAAA P53RE

-1250 AGCAAAGATG AAATTCCAAC TGTCAAAATC TCССTTCCAT CTAATTAATT -1200 CCTCATCCAA CTATGTTCCA AAACGAGAAT AGAAAATTAG CC CCAATAAG

1150 CCCAGGCAAC NF-Y (CHOP) -1050 AAACTCGAAT TTATTTTACC AGTATCTCCT ATGAAGGGCT AGTAACCAAA -1000 ATAATCCACG CATCAGGGAG AGAAATGCCT GAAGGCATAC GTTTTGGACA P53RE

-950 TTtAgCGTCC CTGCAAATTC TGGCCATCGC CGCTTCCTTT GTCCATCAGA P53RE

-900 AGgCAGGAAA CTTTATATTG GTGACCCGTG GAGCTCACAT TAACTATTTA

-850 CAGGGTAACT GCTTAGGACC AGTATTATGA GGAGAATTTA CCTTTCCCGC

-800 СTCTCTTTCC AAGAAACAAG GAGGGGGTA AGGTACGGAG AACAGTATTT STAT

-750 CTTCTGTTGA AAGCAACTTA GCTACAAAGA TAAATTACAG CTATGTACAC -700 TGAAGGTAGC TATTTCATTC CACAAAATAA GAGTTTTTTA AAAAGCTATG

-650 TATGTATGTG CTGCATATAg AGCAGATATA CAGCCTATTA AGCGTCGTCA

-600 CTAAAACATA AAACATGTCA GCCTTTCTTA ACCTTACTCG CCCCAGTCTG

-550 TCCCGACGTG ACTTCCTCGA CCCTCTAAAG ACGTACAGAC CAGACACGGC

-500 GGCGGCGGCG GGAGAGGGGA TTCCCTGCGC CCCCGGACCT CAGGGCCGCT

-450 CAGATTCGTG GAGAGGAAGC CAAGTGTCCT TCTGCCCTCC CCCGGTATCC

-400 CATCCAAGGC GATCAGTCCA GAACTGGCTC TCGGAAGCGC TCGGGCAAAG

-350 ACTGCGAAGA AGAAAAGACA TCTGGCGGAA ACCTGTGCGC CTGGGGCGGT

-300 GGAACTCAGG GAGGAGAGGG AGGGATCAGA CAGGAGAGT GGGGACTACCC P53RE NF-kB

-250 CCTCTGCTCC CCAATTGGG CAGCTTCCTG GGTTTCCGAT TTTCTCATTT

-200 CCGTGGGTAA AAAACCGTGC CCCCACCGG CTTACGCAAT TTTTTTAAGG P63RE

C/EBPbeta

-150 GgAGAgGAgG GAAAAATTTG TGgGgGGTAC GAAAAGGCGg AAAGAAACAG

-100 TCATTTCGTC ACATGGGCTT GGTTTTCAGT CTTATAAAAA GGAAGGTTCT

-50 CTCGGTTAGC GACCATTTGT CATACGACTT GCAGTGAGCG TCAGGAGCA

+1 CGTCCAGGAAC TCCTCAGCAG CGCCTCCTTC AGCTCCACAG CCAGACGCCC

+50 TCAGACAGCA AAGCCTACCC CCGCGCCGCG CCCTGCCCGC CGCTGCGATA

+100 AACTTTGATT GTTTCTATAC ATCTTTGTCA TATGACATAA GATTTCTCTG

Figure 3. Schematic structure of COX-2/PTGS-2 promoter. Sequence of the human $1,700 \mathrm{bp}$ COX-2/PTGS-2 promoter was found in the UCSC human genome website and certain potential transcription factor cis-elements were defined using the TFSEARCH website. The transcription factor sequences are shown in boxes. The TSS (transcription start site) is shown in bold and shadow capital letter and underlined. Coding sequence is shown in italics.

increased cell migration/cell invasiveness of lung cancer cells potentially through EMT-dependent mechanism. ${ }^{16}$

We further examined whether MSE or SSE exposure leads to change of cellular characteristics of lung cancer cells and whether siRNA knockdown of PEA3 or COX-2 expression would affect these potential changes. A427 lung cancer cells with altered LKB1 protein kinase ${ }^{16}$ were transiently transfected with scramble siRNA (Fig. 6A-C, samples 1, 4 and 7), PEA3 siRNA 


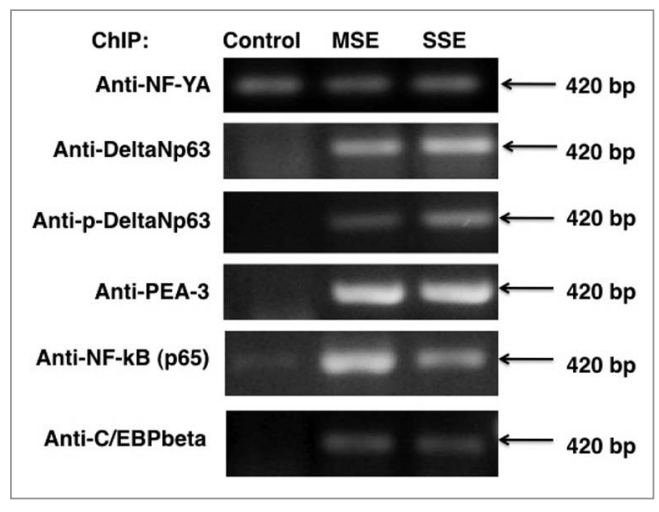

Figure 4. Cigarette smoke exposure induces binding of endogenous transcription factors to the COX-2/PTGS-2 promoter. ChIP assay of the binding of NF-YA, $\Delta$ Np63 $\alpha$ or phospho- $\Delta N p 63 \alpha$ and PEA3 to COX-2/ PTGS-2 promoter using indicated antibodies. A427 lung cancer cells (expressing LKB1 with altered protein kinase ability) were exposed to control medium, $1 \%$ SSE and $0.5 \%$ MSE for $24 \mathrm{~h}$. PCR was used to amplify regions of the COX-2/PTGS-2 promoter around the PEA3-binding sites. Negative control (normal rabbit and normal mouse lgGs) was used to confirm the binding specificity (data not shown).

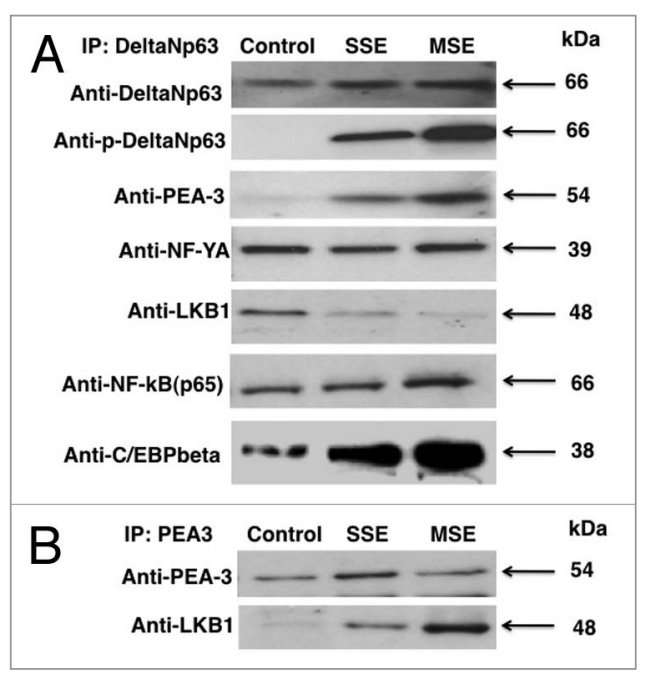

Figure 5. Transcription factors form complexes in lung cancer cells upon cigarette smoke exposure. A427 cells were exposed to control medium, 1\% SSE and $0.5 \%$ MSE for $24 \mathrm{~h}$. (A) Immunoprecipitation (IP) was performed with $\mathrm{Ab}-1$ antibody exclusively recognizing $\Delta \mathrm{Np} 63 \alpha$ protein. Complexes were detected with indicated antibodies. (B) Immunoprecipitation (IP) was performed with PEA3 antibody. Complexes were detected with indicated antibodies.

(Fig. 6A-C, samples 2, 5 and 8) and COX-2/PTGS-2 (Fig. 6A-C, samples 3, 6 and 9) for $48 \mathrm{~h}$. Cells then were exposed to control medium (sample 1-3), 1\% SSE (samples 4-6), 0.5\% MSE (samples 7-9). We then tested the ability of A427 cells to migrate in Matrigel, form foci/clones in soft agar, and undergo apoptosis/survival after cigarette smoke exposure. We found that both SSE and MSE increased cell migration/cell invasiveness (Fig. 6A, samples 4 and 7), cellular ability to form foci/ clones in soft agar (Fig. 6B, samples 4 and 7) and cell survival
(Fig. 6C, samples 4 and 7). However, siRNA against PEA3 (samples 5 and 8) and COX-2 (samples 6 and 9) dramatically modulated this increase in cell migration, foci formation and cell survival (Fig. 6A-C).

\section{Discussion}

Cigarette primary and secondhand smoking is a direct cause of lung cancer associated with inactivation of tumor suppressor genes (e.g., LKB1) via genetic/epigenetic changes therefore affecting many cellular processes including oxidative and DNA damage, inflammatory processes, cell migration and invasiveness. Search and "assessment of novel biomarkers" and therapeutic targets affected by oxidative stress/DNA damage implicated in the cellular response to tobacco-induced pathologies "may have critical clinical utility for the formulation of novel therapeutic options." ${ }^{33}$

This is the first study to be undertaken to support a notion that cigarette smoking is an initiating event for loss of LKB1 expression/function and the LKB1-mediated transcriptional regulation of inflammatory molecules, such as COX-2/PTGS2. We hypothesized that cigarette smoking affects the molecular processes underlying EMT of lung cancer/epithelial cells, therefore linking together inactivation of LKB1 tumor suppressor and PEA3-mediated transcriptional regulation of inflammatory signaling molecules (e.g., COX-2/PTGS-2).

Using MSE and SSE as modeling tools for primary and secondhand smoking, we found that both MSE and SSE downregulated protein levels for LKB1, while upregulated protein levels for PEA3 and COX-2/PTGS-2. We further found that MSE and SSE induced these changes in a dose-dependent manner. We next determined that the COX-2/PTGS-2 promoter sequence contains many regulatory sequences recognized by key transcriptional regulators, such as C/EBP $\beta$, NFKB, NF-YA, PEA3 (ETS), STAT and $\mathrm{p} 53$.

In addition to several p53 consensus sequences $(-1,446$ to $-1,431 ; 1,283$ to $-1,266 ;-986$ to -969 and -941 to -928$)$, we defined a couple of p63 responsive elements (RE) in the COX-2 promoter sequence located at the positions -460 to -441 and -200 to -182 .

As a member of the p53 gene family, p63 regulates downstream target gene expression by binding to sequence-specific response elements similar to those of p53 (reviewed in ref. 37). However, p63RE was shown to be distinct from the canonical p53RE, suggesting that $\mathrm{p} 53$ preferentially binds to the RRR CAT GYY Y sequence, whereas p63 preferentially recognizes RRR CGT GYY Y (reviewed in ref. 37). Using the endogenous ChIP analysis of the COX-2/PTGS-2 promoter in lung cancer cells upon cigarette smoke exposure (MSE and SSE), we found that the C/EBP $\beta$, NFкB, NF-YA, PEA3 (ETS) and $\Delta$ Np63 proteins bound to the narrow area of the COX-2/PTGS-2 promoter spanning from -550 to -130 upstream of the transcription start site (Fig. 3). We then showed that after cigarette smoke exposure (MSE and SSE) of lung cancer cells, these transcription factors C/EBP $\beta$, NFкB, NF-YA, PEA3 (ETS) and $\Delta$ Np63 formed protein complexes. While levels of $\Delta \mathrm{Np} 63, \mathrm{p}-\Delta \mathrm{Np} 63$ (reviewed in ref. 35), C/EBP $\beta$ and PEA3 increased, the levels of $\mathrm{NF \kappa B}$ and NF-YA remained the same after cigarette smoke exposure. 
Several transcription factors $(\mathrm{C} / \mathrm{EBP} \beta, \mathrm{NF \kappa B}, \mathrm{STAT} 3, \mathrm{p} 53$ and PEA3) shown to activate COX-2 expression were previously reported playing critical roles in gene expression during lung cancer cellular response to tobacco smoking exposure. ${ }^{21-24,27,28,38-43}$ Moreover, PEA3 was found to be activated by cigarette smoke exposure and regulate MMP-1 transcription by binding to a smoke response region in the distal MMP-1 promoter suggesting that PEA3 function has implications for smoking-related cancer, heart disease and emphysema. ${ }^{30}$ Furthermore, by association with other chromatin/transcription regulators, PEA3 was shown to activate Twist expression and promote cell migration/cell invasiveness in human cancer cells suggesting its role in cancer metastasis. ${ }^{11,44,45}$ PEA3 along with CBP/p300 was also shown to be a key transcriptional regulator of many genes (MMP-1, 2, 7 and 9, COX-2/ PTGS-2) implicated in inflammation and cell invasiveness. ${ }^{46-49}$

The current study defines a novel link between various transcription factors occupying the COX-2/PTGS-2 promoter and cellular response to cigarette smoke exposure bringing a new component, $\Delta \mathrm{Np} 63 \alpha$, showing a critical role for cooperation between various chromatin components in regulation of COX-2/ PTGS-2 expression and, therefore strengthening the central role of inflammatory process and oxidative stress in tumorigenesis of epithelial cells, especially after cigarette smoke exposure (both primary and secondhand).

Numerous signaling pathways are implicated in cellular response to oxidative and genotoxic stress potentially induced by smoke exposure. For example, the ROS-induced interplay between the DNA-damage and oxidative stress through an activation of ATM-dependent phosphorylation of p 53 family members and TSG tumor suppressor via the PARP1-LKB1-AMPK-mTOR metabolic pathway known to stimulate autophagy. ${ }^{50-52}$

Furthermore, as a substrate for ATM-dependent phosphorylation, $\Delta \mathrm{Np} 63 \alpha$ was shown serving as a pro-survival factor by upregulating a glutathione peroxidase (GPX2) to reduce the p53-dependent oxidative stress-induced apoptotic response. ${ }^{53}$ p 63 was also shown to transcriptionally regulate REDD1 that implicates ROS in the p53-dependent DNA damage response and in p63-mediated regulation of epithelial differentiation..$^{54} \mathrm{ROS}$ were found to activate p53 family members (p53, p63 ands p73) inducing the expression of ferredoxin reductase (FDXR), which in turn sensitizes cells to ROS-mediated apoptosis. ${ }^{55}$

As a target for p53 family proteins, COX-2 was shown producing oxidative damage and affecting the stress-induced cellular senescence. ${ }^{56}$ Hyperoxia was also shown to induce the cellular senescence through the p53-LKB1-AMPK pathway. ${ }^{57}$

ROS were further shown to stimulate cancer cell growth by regulating AMPK-COX-2 pathway. ${ }^{58}$ Sp1/Sp3-dependent transcriptional regulation of COX-2 was shown playing an essential role in the modulation of COX-2 expression that mediates neuronal homeostasis and survival by preventing DNA damage. ${ }^{59}$ Furthermore, oxidative stress was shown to induce cGMPprotein kinase-mediated thioredoxin peroxidase 1 transcription through PEA3, AP-1, c-Myc and c-Jun transcription factors. ${ }^{60}$

Accumulated data strongly suggest that continuous (chronic) upregulation of pro-inflammatory mediators (e.g., TNFalpha,

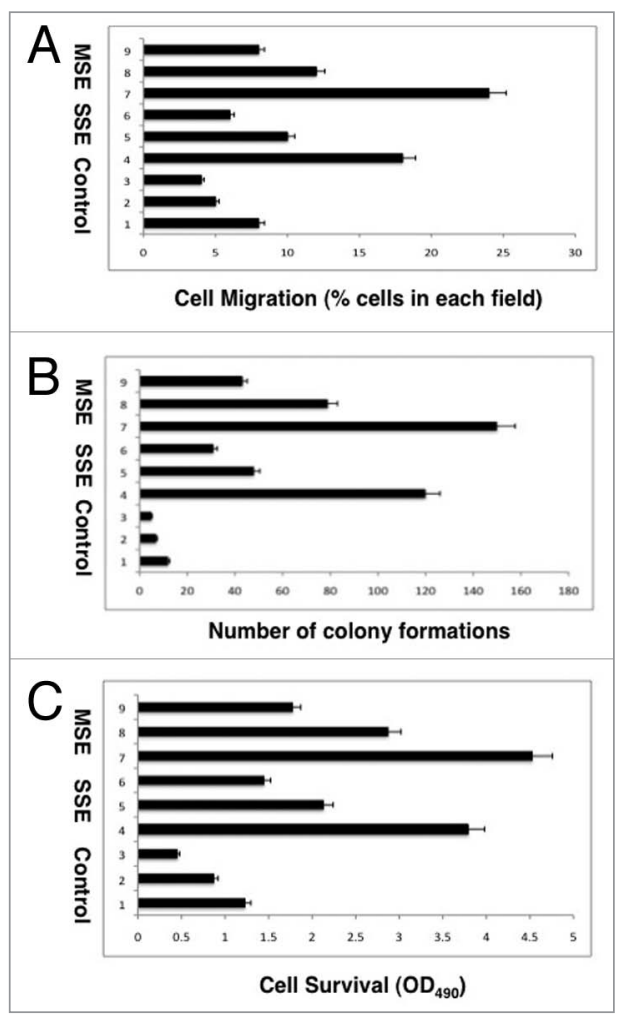

Figure 6. Cigarette smoke affects the cellular characteristics of lung cancer cells. (A) Migration assay. (B) Soft agar growth assay. (C) MTT Survival Assay. A427 cells were transiently transfected with scramble siRNA (samples 1, 4 and 7), PEA3 siRNA (samples 2, 5 and 8) and COX-2/ PTGS-2 (samples 3, 6 and 9) for $48 \mathrm{~h}$. Cells then were exposed to control medium (sample 1-3), 1\% SSE (samples 4-6), 0.5\% MSE (samples 7-9). Experiments were performed in triplicate.

IL-1beta, IL-6, COX-2, NOS-2) are induced during the aging process due to an age-related redox imbalance that activates many pro-inflammatory signaling pathways, including the NFкB signaling pathway. ${ }^{61}$ Both ROS and pro-inflammatory genes (e.g., COX-2) were found contributing to the expansion of cellular inflammatory responses and reduce the expression of genes required to maintain synaptic structure and function ultimately leading to progressive dysfunction, apoptosis and/or necrosis and brain cell death. ${ }^{62}$ Pro-inflammatory genes shown playing a role in neurodegeneration (e.g., Alzheimer disease) are transiently activated by the heterodimeric oxygen-sensitive protein-protein complexes between NFKB and HIF-1 $\alpha$ (reviewed in ref. 62).

Many cellular responses to tobacco smoke, such as oxidative stress/ DNA damage, EMT, altered adhesion-mediating signaling pathways and altered protein degradation, chromatin modifications/epigenetic changes, angiogenesis and autophagy/apoptosis complement the inflammatory/neoplastic processes as the key underlying mechanisms in both chronic obstructive pulmonary disease, cardiovascular disease, lung cancer, aging and age-related diseases. ${ }^{4} 13,24,28,51,56-58,61,62$ Thus, understanding the cellular and molecular mechanisms underlying these processes will provide novel venues for devising therapeutic strategies against smoke-related diseases. 


\section{Materials and Methods}

Preparation of CSE. Mainstream smoke extract (MSE) and sidestream smoke extract (SSE) made from research-grade cigarettes (2R4F, from Tobacco Health Research, University of Kentucky, Louisville) contain nicotine: $0.85 \mathrm{mg} /$ cigarette and tar: $9.70 \mathrm{mg} /$ cigarette as previously described. ${ }^{63} \mathrm{SSE}$ was collected from the burning end of the cigarettes without puffing at the rate of $200 \mathrm{ml} / \mathrm{min}$ and MSE was collected with $35 \mathrm{ml} / \mathrm{min}$ puff per 2 sec using the opposite end of two smoking machines (MasterFlex Pump Systems, Cole-Parmer Instrument). Briefly, the smoke of 20 cigarettes for MSE and 40 cigarettes for SSE was bubbled into each flask containing $20 \mathrm{ml}$ of pre-warmed phosphate buffer saline. The aqueous smoke extract was filtered through $0.22 \mu \mathrm{m}$ pore syringe filter to remove large particles. The smoke bubbled into MSE flask was acidic and that into SSE flask appeared to be basic, therefore the $\mathrm{pH}$ of each solution was adjusted to 7.4. The solution was aliquoted and kept frozen at $-80^{\circ} \mathrm{C}$ until use. The concentration of SSE was monitored at the absorbance of 1 at $A_{230}$ was considered $100 \%$. The concentration of MSE solution was considered $100 \%{ }^{63}$ MSE and SSE were used to imitate cigarette primary smoking and secondhand smoking, respectively.

Cell cultures and transfections. Human lung cancer cell lines (A427 and H1299) and normal human bronchiolar epithelial (NHBE) cells were purchased from the American Type Culture Collection (ATCC) were grown in the recommended media. The $200 \mathrm{pmol} / \mathrm{six}$-well plate of scramble siRNA, siRNA against PEA3 (sc-36205) and COX-2 (sc-29279) were purchased from Santa Cruz Biotechnology and were transiently introduced into cells for $24 \mathrm{~h}$ using FuGENE-6 (Roche Molecular Biochemicals) as previously described. ${ }^{16}$ Cells were then exposed to control medium or various concentrations of both MSE and SSE for indicated periods of time. ${ }^{63}$

Chromatin immunoprecipitation (ChIP) assay. H1299 cells $\left(2 \times 10^{6}\right)$ were transfected exposed to control medium, MSE and SSE. ChIP was done using a ChIP assay kit (Upstate Cell Signaling Solutions). H1299 cells $\left(2 \times 10^{6}\right)$ were cross-linked with $1 \%$ formaldehyde and ChIP was performed as previously described. ${ }^{16,35}$ After reversing the cross-links, chromatin was purified using the QIAquick PCR Purification kit (Qiagen, Inc.) and samples were eluted with $30 \mu \mathrm{l}$ of elution buffer. Chromatin was immunoprecipitated with $1 \mu \mathrm{g}$ of primary antibodies against PEA3 (clone 1A2G3, sc-130661, Santa Cruz Biotechnology), NFkB p65 subunit (ab7970, Abcam), $\Delta$ Np63, C/EBP/ 3 (\#3087, Cell Signaling Technology) and NF-YA (ab6558, Abcam). Immunoprecipitates were used as templates for PCR amplification of the COX-2 promoter with the following primers: COX-2, sense primer, (-550) 5'-TCC CGA CGT GAC TTC CTC GA $(-530)$ and antisense primer, (-150) 5'-GGA GAG GAG GGA AAA ATT TG-3' (-130) yielding the PCR product of $420 \mathrm{bp}$, which was amplified as follows: $94^{\circ} \mathrm{C}$ for 1 minute, $55^{\circ} \mathrm{C}$ for 1 minute and $72^{\circ} \mathrm{C}$ for 30 seconds using Platinum Taq I DNA polymerase (Invitrogen) for 37 cycles. $^{16}$

Immunoblotting and immunoprecipitation. We used primary antibodies against PEA3 (clone 1A2G3, sc-130661) and $\Delta \mathrm{Np} 63$ (clone (3F306): sc-71825) from Santa Cruz Biotechnology; against LKB1 (clone 27D10, ab\#3050) and C/EBP/ $\beta$ (\#3087) from Cell Signaling Technology; NFкB p65 subunit (ab7970) and NF-YA (ab6558) from Abcam; against $\beta$-actin (Sigma), COX-2/PTGS-2 (Cayman Chemical) or $\Delta \mathrm{Np} 63$ (Ab-1, EMD) for immunoblotting analysis and immunoprecipitation. ${ }^{16,35}$ Immunoblots were scanned and quantification was carried out by Image Quant software version 3.3 (Molecular Dynamics). Values were expressed as percentage of a control sample (defined as $100 \%) .5 \times 10^{5}$ cells per well were plated into six-well plates and exposed to control medium, MSE and SSE. Cells were lysed in buffer $[50 \mathrm{mmol} / \mathrm{l}$ Tris ( $\mathrm{pH} 7.5$ ), $150 \mathrm{mmol} / \mathrm{l} \mathrm{NaCl}, 5 \mu \mathrm{g} / \mathrm{ml}$ aprotinin, pepstatin, $1 \%$ Nonidet P-40, $1 \mathrm{mmol} / \mathrm{l}$ EDTA, $0.25 \%$ deoxycholate]. For immunoprecipitation, total cell lysates $(500 \mu \mathrm{l})$ were precipitated with $5 \mu \mathrm{g}$ of the indicated primary antibodies overnight at $4^{\circ} \mathrm{C}$ followed by incubation with anti-rabbit or anti-mouse immunoglobulins (IgG)-coupled to agarose beads (Sigma) and washed with lysis buffer before being resolved by SDS-PAGE. ${ }^{16,35}$

Cell invasion/Matrigel assay. Cells $\left(1 \times 10^{4}\right)$ in $0.5 \mathrm{ml}$ of serum-free MEM were added to each well of $24-$ well $/ 8-\mu \mathrm{m}$ pore invasion membrane chambers coated with Matrigel (BD Discovery Labware). The lower chambers contained $10 \%$ fetal bovine serum (FBS) in MEM to serve as a chemoattractant. Cells were allowed to migrate or invade over the course of $48 \mathrm{~h}$. Chambers were fixed with $100 \%$ methanol for 2 min, stained with $0.5 \%$ crystal violet for $2 \mathrm{~min}$, rinsed in water and examined under a bright-field microscope. Values for invasion and migration were obtained by counting five fields per membrane (20x objective) and represented the average of three independent experiments done over multiple days. ${ }^{16,63}$

Colony formation assay. Soft agar colony formation assays were carried out in six-well dishes. Cells $\left(1 \times 10^{4}\right)$ suspended in $2 \mathrm{ml}$ of $0.36 \%$ bactoagar (Becton Dickinson) with growth medium (RPMI 1640 supplemented with 10\% FBS) were added on a base layer of $0.72 \%$ bactoagar containing culture medium. ${ }^{63}$ The plates were incubated at $37^{\circ} \mathrm{C}$ in a $5 \% \mathrm{CO}_{2}$ incubator for 3 weeks. Colonies were counted under low magnification (x100).

MTT survival assay. The number of cells in each well after treatment was estimated using the 3-(4, 5-dimethylthiazol2-yl)-2,5-diphenyltetrazolium bromide (MTT) assay (ATCC) as previously described. ${ }^{35,63}$ MTT labeling reagent (final concentration, $0.5 \mathrm{mg} / \mathrm{ml}$ ) was added to cells in 96-well culture plates (final volume, $100 \mu \mathrm{l}$ culture medium/well) and incubated for $4 \mathrm{~h}$ at $37^{\circ} \mathrm{C}$ in a humidified atmosphere of $10 \% \mathrm{CO}_{2}$. Cells were then solubilized overnight and the samples were quantified at $570 \mathrm{~nm}$ using a microtiter plate reader (Bio-Rad Laboratories).

\section{Note}

Supplementary materials can be found at: http://www.landesbioscience.com/supplement/RatovitskiOMCL3-5-Sup.pdf

\section{Acknowledgements}

This work was in part supported by grant \#082469 from Flight Attendant Medical Research Institutions. 


\section{References}

1. Hecht SS. Tobacco smoke carcinogens and lung cancer. J Natl Cancer Inst 1999; 91:1194-210.

2. Boffetta P. Human cancer from environmental pollutants: the epidemiological evidence. Mutat Res 2006; 608:157-62.

3. Zhou W, Heist RS, Liu G, et al. Second hand smoke exposure and survival in early-stage non-small-cell lung cancer patients. Clin Cancer Res 2006; 12:7187-93.

4. Cianchi F, Cortesini C, Bechi P, et al. Upregulation of COX-2 gene expression correlates with tumor angiogenesis in human colorectal cancer. Gastroenterology 2001; 121:1339-47.

5. De Marzo A, Platz E, Sutcliffe S, et al. Inflammation in prostate carcinogenesis. Nature Reviews Cancer 2007; 7:256-69.

6. Yao H, Rahman I. Current concepts on the role of inflammation in COPD and lung cancer. Curr Opin Pharmacol 2009; 9:375-83

7. Elahi MM, Kong YX, Matata BM. Oxidative stress as a mediator of cardiovascular disease. Oxid Med Cell Longev 2009; 2:259-69.

8. Achary A, Das I, Chandhok D, Saha T. Redox regulation in cancer: A double-edged sword with therapeutic potential. Oxid Med Cell Longev 2010; 3:23-34.

9. Maiuri MC, Tasdemir E, Criollo A, et al. Control of autophagy by oncogenes and tumor suppressor genes. Cell Death Differ 2009; 16:87-93.

10. Essick EE, Flora Sam F. Oxidative stress and autophagy in cardiac disease, neurological disorders, aging and cancer. Oxid Med Cell Longev 2010; 3; In Press.

11. Yang J, Mani SA, Donaher JL, et al. Twist, a master regulator of morphogenesis, plays an essential role in tumor metastasis. Cell 2004; 117:927-39.

12. Yoshino I, Kometani T, Shoji F, et al. Induction of epithelial-mesenchymal transition-related genes by benzo[a]pyrene in lung cancer cells. Cancer 2007; 110:369-74.

13. Lee JM, Yanagawa J, Peebles KA, Sharma S, Mao JT, Dubinett SM. Inflammation in lung carcinogenesis: new targets for lung cancer chemoprevention and treatment. Crit Rev Oncol Hematol 2008; 66:208-17.

14. Liu G, Zhou W, Christiani DC. Molecular epidemiology of non-small cell lung cancer. Semin Respir Crit Care Med 2005; 26:265-72.

15. Sanchez-Cespedes M, Parrella P, Esteller M, et al. Inactivation of LKB1/STK11 is a common event in adenocarcinomas of the lung. Cancer Res 2002; 62:3659-62.

16. Upadhyay S, Liu C, Chatterjee A, Hoque M, Kim M, Engles J, et al. LKB1/STK11 suppresses COX-2 induction and cellular invasion through PEA3 in lung cancer. Cancer Res 2006; 66:7870-9.

17. Ghaffar H, Sahin F, Sanchez-Cespedes M, Su GH, Zahurak M, Sidransky D, Westra WH. LKB1 protein expression in the evolution of glandular neoplasia of the lung. Clin Cancer Res 2003; 9:2998-3003.

18. Gurumurthy S, Hezel AF, Sahin E, Berger JH, Bosenberg MW, Bardeesy N. LKB1 deficiency sensitizes mice to carcinogen-induced tumorigenesis. Cancer Res 2008; 68:55-63.

19. Ji H, Ramsey MR, Hayes DN, Fan C, et al. LKB1 modulates lung cancer differentiation and metastasis. Nature 2007; 448:807-10.

20. Scott KD, Nath-Sain S, Agnew MD, Marignani PA. LKB1 catalytically deficient mutants enhance cyclin D1 expression. Cancer Res 2007; 67:5622-7.

21. Zeng PY, Berger SL. LKB1 is recruited to the $\mathrm{p} 21^{\mathrm{WAF} 1}$ promoter by $\mathrm{p} 53$ to mediate transcriptional activation. Cancer Res 2006; 66:10701-8.

22. Dalwadi H, Krysan K, Heuze-Vourc'h N, et al. COX2-dependent activation of STAT3 by IL-6 in non-small cell lung cancer. Clin Cancer Res 2005; 11:7674-82.

23. Hida T, Kozaki K, Muramatsu H, et al. COX-2 inhibitor induces apoptosis and enhances cytotoxicity of various anticancer agents in non-small cell lung cancer cell lines. Clin Cancer Res 2000; 6:2006-11.
24. Moodie FM, Marwick JA, Anderson CS, et al. Oxidative stress and cigarette smoke alter chromatin remodeling but differentially regulate $\mathrm{NF} \kappa \mathrm{B}$ activation and proinflammatory cytokine release in alveolar epithelial cells. FASEB J 2004; 18:1897-9.

25. Subbaramaiah K, Norton L, Gerald W, Dannenberg AJ. COX-2 is overexpressed in HER-2/neu-positive breast cancer: evidence for involvement of AP-1 and PEA3. J Biol Chem 2002; 277:18649-57.

26. Tsujii M, Kawano S, DuBois RN. COX-2 expression in human colon cancer cells increases metastatic potential. Proc Natl Acad Sci USA 1997; 94:3336-40.

27. Wolff H, Saukkonen K, Anttila S, et al. Expression of COX-2 in human lung carcinoma. Cancer Res 1998; 58:4997-5001.

28. Yang SR, Chida AS, Bauter MR, et al. Cigarette smoke induces proinflammatory cytokine release by activation of NFKB and posttranslational modifications of histone deacetylase in macrophages. Am J Physiol Lung Cell Mol Physiol 2006; 291:46-57.

29. Baglole CJ, Maggirwar SB, Gasiewicz TA, Thatcher TH, Phipps RP, Sime PJ. The aryl hydrocarbon receptor attenuates tobacco smoke-induced COX-2 and prostaglandin production in lung fibroblasts through regulation of the NFкB family member RelB. J Biol Chem 2008; 283:28944-57.

30. Mercer BA, Wallace AM, Brinckerhoff CE, D'Armiento JM. Identification of a cigarette smoke-responsive region in the distal MMP-1 promoter. Am J Respir Cell Mol Biol 2009; 40:4-12.

31. Liu ES, Shin VY, Ye YN, Luo JC, Wu WK, Cho CH COX-2 in cancer cells and macrophages induces colon cancer cell growth by cigarette smoke extract. Eur J Pharmacol 2005; 518:47-55.

32. Carpagnano GE, Spanevello A, Palladino GP, Gramiccioni C, Ruggieri C, Carpagnano F, Foschino Barbaro MP. Cigarette smoke and increased COX-2 and survivin levels in exhaled breath condensate of lung cancer patients: how hot is the link? Lung Cancer 2010; 67:108-13.

33. Maiese K. Marking the onset of oxidative stress: Biomarkers and novel strategies. Oxid Med Cell Longev 2009; 2:1

34. Hibi K, Trink B, Patturajan M, Westra W, Hill D, Ratovitski EA, et al. AIS is an oncogene amplified in squamous cell carcinoma. Proc Natl Acad Sci USA 2000; 97:5462-7.

35. Huang Y, Hao H, Chuang A, Romano R, Wu G, Sinha $S$, et al. Phospho- $\Delta \mathrm{DNp} 63$-dependent transcriptional regulation of gene expression in head and neck squamous cell carcinoma cells upon cisplatin exposure. Cell Cycle 2010; 9:238-328.

36. Karuman P, Gozani O, Odze RD, et al. The Peutz Jegher gene product LKB1 is a mediator of $\mathrm{p} 53$-dependent cell death. Mol Cell 2001; 7:1307-19.

37. Osada M, Yamashita K, Park H, Fomenkov A, Kim $\mathrm{M}, \mathrm{Wu} \mathrm{G}$, et al. Differential recognition of response elements determines target gene specificity for $\mathrm{p} 53$ and p63. Mol Cell Biol 2005; 25:6077-89.

38. Hiroumi H, Dosaka-Akita $\mathrm{H}$, Yoshida $\mathrm{K}$, et al. Expression of E1AF/PEA3, an Ets-related transcription factor in human non-small-cell lung cancers: its relevance in cell motility and invasion. Int J Cancer 2001; 93:786-991.

39. Howe LR, Crawford HC, Subbaramaiah K, et al. PEA3 is upregulated in response to Wntl and activates the expression of cyclooxygenase-2. J Biol Chem 2001; 276:20108-15.

40. Liu Y, Borchert GL, Phang JM. PEA3, an ets transcrip tion factor, mediates the induction of COX-2 by nitric oxide in colorectal cancer cells. J Biol Chem 2004; 279:18694-700

41. Connors SK, Balusu R, Kundu CN, Jaiswal AS, Gairola CG, Narayan S. C/EBP $\beta$-mediated transcriptional regulation of bcl- $x_{1}$ gene expression in human breast epithelial cells in response to cigarette smoke condensate. Oncogene 2009; 28:921-32.
42. Tsurutani J, Castillo SS, Brognard J, Granville CA, Zhang C, Gills JJ, et al. Tobacco components stimulate Akt-dependent proliferation and NFKB-dependent survival in lung cancer cells. Carcinogenesis 2005; 26:1182-95.

43. Anto RJ, Mukhopadhyay A, Shishodia S, Gairola CG, Aggarwal BB. Cigarette smoke condensate activates $\mathrm{NF} \kappa \mathrm{B}$ through phosphorylation and degradation of I $\mathrm{B} \alpha$ : correlation with induction of cyclooxygenase-2. Carcinogenesis 2002; 23:1511-8.

44. Han JA, Kim JI, Ongusaha PP, et al. p53-mediated induction of COX-2 counteracts p53- or genotoxic stress-induced apoptosis. EMBO J 2002; 21:5635-44.

45. de Launoit Y, Baert JL, Chotteau-Lelievre A, et al. The Ets transcription factors of the PEA3 group: transcriptional regulators in metastasis. Biochim Biophys Acta 2006; 1766:79-87.

46. Qin L, Liu Z, Chen H, Xu J. The steroid receptor coactivator-1 regulates twist expression and promotes breast cancer metastasis. Cancer Res 2009; 69:3819-27.

47. Wang XQ, Li H, Van Putten V, Winn RA, Heasley LE, Nemenoff RA. Oncogenic K-Ras regulates proliferation and cell junctions in lung epithelial cells through induction of COX-2 and activation of MMP-9. Mol Biol Cell 2009; 20:791-800.

48. Wang R, Wang X, Lin F, Gao P, Dong K, Zhang HZ. shRNA-targeted COX-2 inhibits proliferation, reduces invasion and enhances chemosensitivity in laryngeal carcinoma cells. Mol Cell Biochem 2008; 317:179-88.

49. Cowden Dahl KD, Zeineldin R, Hudson LG. PEA3 is necessary for optimal epidermal growth factor receptorstimulated matrix metalloproteinase expression and invasion of ovarian tumor cells. Mol Cancer Res 2007; 5:413-21.

50. Lynch CC, Crawford HC, Matrisian LM, McDonnell S. Epidermal growth factor upregulates MMP-7 expression through activation of PEA3 transcription factors. Int J Oncol 2004; 24:1565-72.

51. Jorgensen ED, Zhao $\mathrm{H}$, Traganos F, Albino AP, Darzynkiewicz Z. DNA damage response induced by exposure of human lung adenocarcinoma cells to smoke from tobacco- and nicotine-free cigarettes. Cell Cycle 2010; 9; In press.

52. Alexander A, Cai SL, Kim J, Nanez A, Sahin M, MacLean $\mathrm{KH}$, et al. ATM signals to TSC2 in the cytoplasm to regulate mTORC1 in response to ROS. Proc Natl Acad Sci USA 2010; 107:4153-8.

53. Huang Q, Wu YT, Tan HL, Ong CN, Shen HM. A novel function of poly(ADP-ribose) polymerase-1 in modulation of autophagy and necrosis under oxidative stress. Cell Death Differ 2009; 16:264-77.

54. Yan W, Chen X. GPX2, a direct target of p63, inhibits oxidative stress-induced apoptosis in a p53-dependent manner. J Biol Chem 2006; 281:7856-62.

55. Ellisen LW, Ramsayer KD, Johannessen CM, Yang A, Beppu H, Minda K, et al. REDD1, a developmentally regulated transcriptional target of p63 and p53, links p63 to regulation of reactive oxygen species. Mol Cell 2002; 10:995-1005.

56. Liu G, Chen X. The ferredoxin reductase gene is regulated by the $\mathrm{p} 53$ family and sensitizes cells to oxidative stress-induced apoptosis. Oncogene 2002; 21:7195204

57. Zdanov S, Bernard D, Debacq-Chainiaux F, Martien $\mathrm{S}$, Gosselin K, Vercamer C, et al. Normal or stressinduced fibroblast senescence involves COX-2 activity. Exp Cell Res 2007; 313:3046-56.

58. Klimova TA, Bell EL, Shroff EH, Weinberg FD, Snyder CM, Dimri GP, et al. Hyperoxia-induced premature senescence requires $\mathrm{p} 53$ and $\mathrm{pRb}$, but not mitochondrial matrix ROS. FASEB J 2009; 23:783-94.

59. Park IJ, Hwang JT, Kim YM, Ha J, Park OJ. Differential modulation of AMPK signaling pathways by low or high levels of exogenous reactive oxygen species in colon cancer cells. Ann N Y Acad Sci 2006; 1091:102-9. 
60. Lee J, Kosaras B, Aleyasin H, Han JA, Park DS, Ratan $\mathrm{RR}$, et al. Role of COX-2 induction by transcription factor Sp1 and Sp3 in neuronal oxidative and DNA damage response. FASEB J 2006; 20:2375-7.

61. Andoh T, Chiueh CC, Chock PB. Cyclic GMPdependent protein kinase regulates the expression of thioredoxin and thioredoxin peroxidase-1 during hormesis in response to oxidative stress-induced apoptosis. J Biol Chem 2003; 278:885-90
62. Chung HY, Cesari M, Anton S, Marzetti E, Giovannini S, Seo AY, et al. Molecular inflammation: underpinnings of aging and age-related diseases. Ageing Res Rev 2009; 8:18-30.

63. Bazan NG, Palacios-Pelaez R, Lukiw WJ. Hypoxia signaling to genes: significance in Alzheimer's disease. Mol Neurobiol 2002; 26:283-98.
64. Kim MS, Huang Y, Lee J, Zhong X, Jiang WW, Ratovitski EA, Sidransky D. Cellular transformation by cigarette smoke extract involves alteration of glycolysis and mitochondrial function in esophageal epithelial cells. Int J Cancer 2010; 127:269-81. 


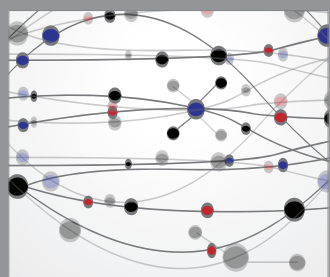

The Scientific World Journal
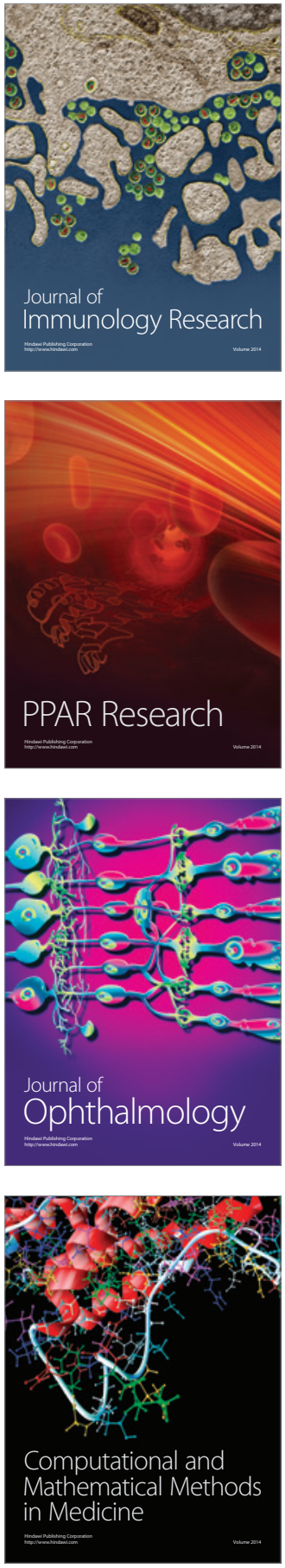

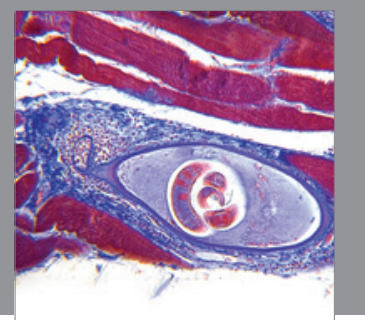

Gastroenterology

Research and Practice
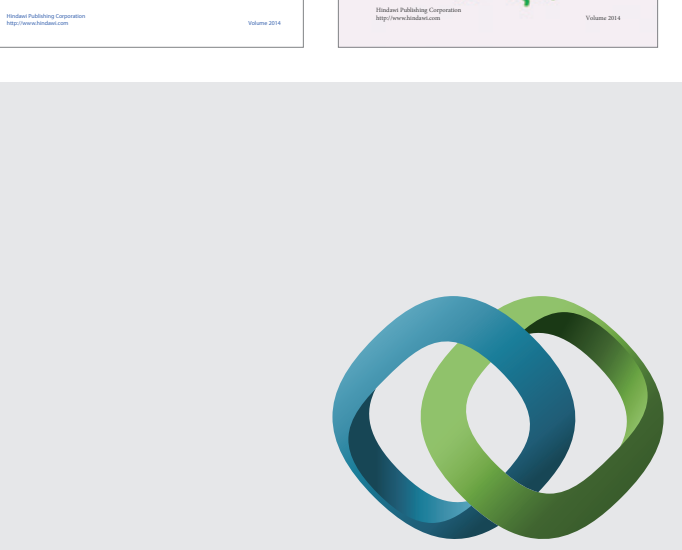

\section{Hindawi}

Submit your manuscripts at

http://www.hindawi.com
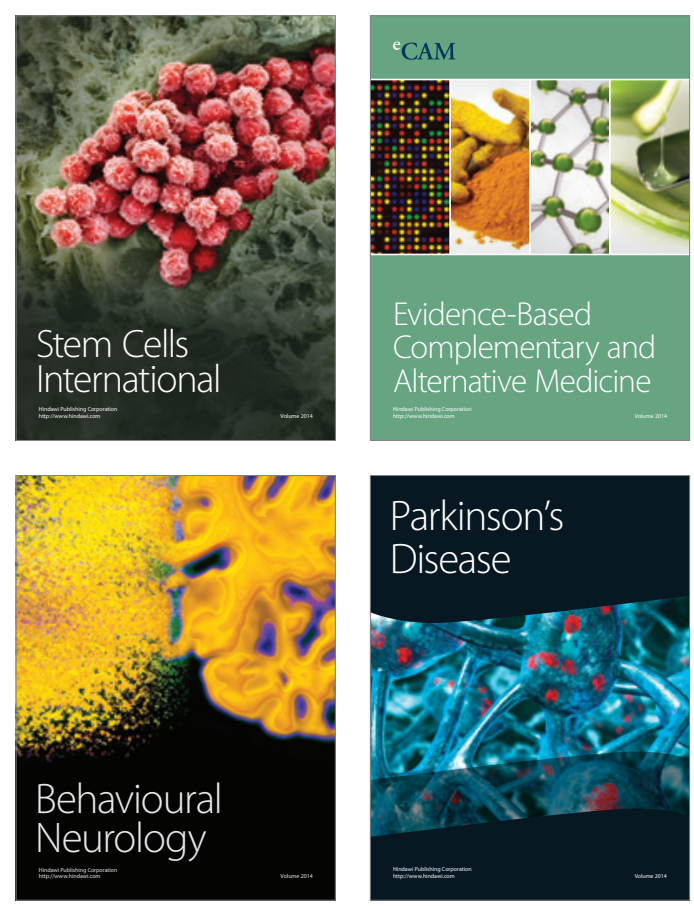

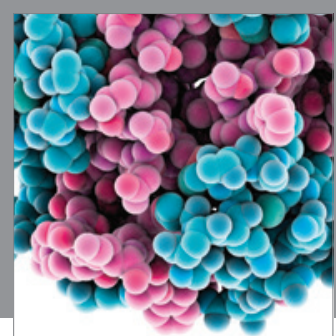

Journal of
Diabetes Research

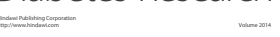

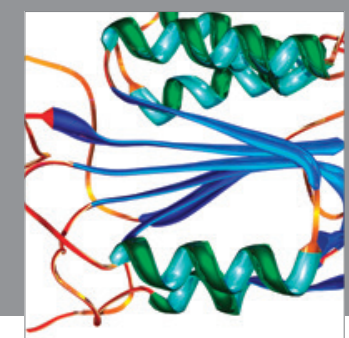

Disease Markers
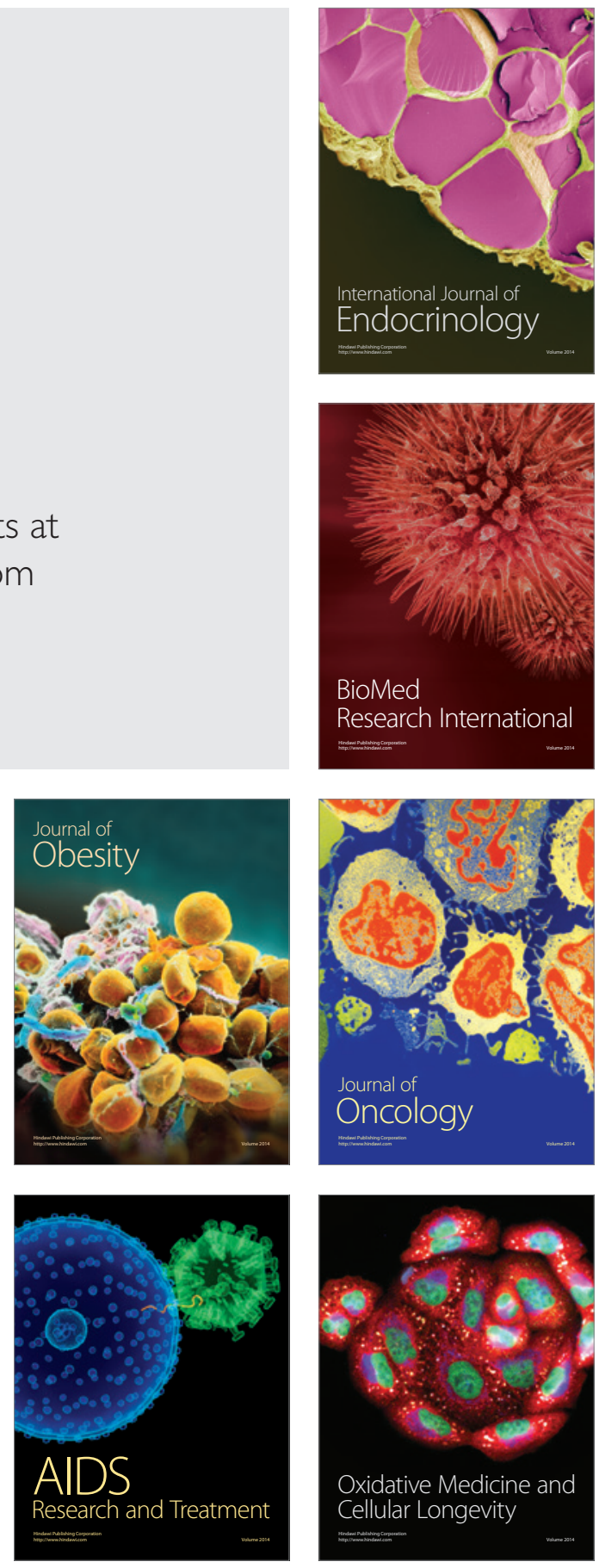